\title{
DE PARÍS AL MADRID DE LA REGENCIA: DON JUAN DE AUSTRIA O LA ADAPTACIÓN LARRIANA DE DELAVIGNE (1835-1837)
}

\author{
Montserrat Ribao Pereira \\ Universidad de Vigo
}

\section{RESUMEN}

En su viaje a París de 1835, Larra conoce a Delavigne y decide traducir su obra más reciente, Don Juan d'Autriche ou La vocation. Para adaptar el texto original a los gustos y al contexto españoles, Fígaro introduce críticas a aspectos concretos de la política o a la sociedad de su tiempo, modifica el nombre de los personajes, la extensión de algunos parlamentos... Pero además de todo ello, suprime diálogos e incluso varias escenas completas que ya habían sido eliminadas del estreno parisino de la pieza. Algunos de los cambios más relevantes en el sentido global del texto (de cuyo estudio nos ocupamos en este trabajo) no son, pues, fruto del talento creador de Larra, sino el resultado de su personal decisión de llevar a la escena española un drama más próximo de lo que se ha creído al representado en Francia.

Palabras Clave: Larra, Delavigne, traducción, Don Juan de Austria

\section{Abstract}

On his trip to Paris in 1835, Larra Delavigne meets and decides to translate his most recent work, Don Juan d'Autriche ou La vocation. To adapt the original text to the Spanish context, Figaro introduces criticism of specific aspects of politics or society of his time, changes the name of the characters, the ex-

Recibido: 04-03-2014 / Aceptado: 21-05-2014 
tension of some parliaments... But he also suppresses several complete dialogues and scenes that had already been eliminated from the Parisian premiere of the piece. Some relevant changes of the text that I analyze do not come from Larra: they are the result of his decision of taking to the Spanish scene a drama very similar to the represented one in France.

KeY wORDS: Larra, Delavigne, Traduction, Don Juan de Austria

Entre 1834 y 1845 se vive en las letras españolas un auténtico «furor de la traducción». ${ }^{1}$ En palabras de Mesonero Romanos, la adaptación de textos foráneos adquiere dimensiones desproporcionadas cuando, como en su tiempo, «Los literatos, en vez de escribir de su propio caudal, se contentan con traducir novelas y dramas extranjeros». ${ }^{2}$ El fenómeno crece en intensidad a lo largo del siglo y Bretón de los Herreros señala que las adaptaciones son tantas y de tan mala calidad «que no es extraño se oiga por algunos con cierta repugnancia el nombre de traductores». ${ }^{3}$

Mariano José de Larra no fue ajeno a esta corriente, a la que presta atención como crítico y como dramaturgo. Son muchos los artículos que Fígaro dedica al tema y en todos ellos coincide en considerar que traducir en materia de teatro

[...] casi nunca es interpretar; es buscar el equivalente, no de las palabras, sino de las situaciones. Traducir bien una comedia es adoptar una idea y un plan ajenos, que estén en relación con las costumbres del país a que se traduce, y expresarlos y dialogarlos precisamente como si se escribiera originalmente; de donde se infiere que por lo regular no puede traducir bien comedias quien no es capaz de escribirlas originales. Lo demás es ser un truchiman, sentarse en el agujero del apuntador, y decirle al público español: dice Mr. Scribe, etc., etc. [...]. ${ }^{4}$

Sin embargo, Larra es muy consciente de la existencia de distintos receptores, culto uno, «l'autre majoritaire, populaire, hélas de mauvais goût, peu regardant, instable, tyranique...». ${ }^{5}$ De esta dialéctica surge, precisamente, la divergencia entre

\footnotetext{
1 J. R. Aymes, «Las opiniones acerca de las traducciones en la prensa española de los años 1823-1844», Neoclásicos y románticos ante la traducción, en F. Lafarga, C. Palacios y A. Saura (eds.), Murcia, Universidad de Murcia, 2002, pp. 35-58, aquí p. 37.

2 R. Mesonero Romanos, «Variedades críticas. Las Traducciones o emborronar papel», Semanario Pintoresco Español, 17 de julio (1842), p. 228.

3 Cito por M. Á. Muro Munilla, Ideas lingüísticas sobre el extranjerismo en Bretón de los Herreros, Logroño, Instituto de Estudios Riojanos, 1985, p. 29. Para la intensidad del fenómeno véase E. Cobos Castro, «Teatro y traducción en el siglo XIX: el papel evaluador de la crítica teatral», Estudios de Investigación Franco-Española, 12 (1995), pp. 11-52.

4 Fígaro, «De las traducciones», El Español, 132, 11 de marzo (1836), pp. 3-4.

5 J. R. Aymes, «Mariano José de Larra et la traduction, ou comment accomoder la pratique à la théorie, et vice versa», Bulletin Hispanique, 104-2 (2002), pp. 829-849, aquí p. 839.
} 
sus postulados teóricos y su práctica escénica como traductor/adaptador del teatro francés, no siempre coincidentes. ${ }^{6}$

Las fronteras entre traducciones, arreglos y adaptaciones no resultan siempre nítidas en la primera mitad del siglo y Romero Tobar ha señalado incluso que la reelaboración a que Larra somete los modelos foráneos es, en realidad, una refundición al estilo de las que en su época se hacían del Siglo de Oro. ${ }^{7}$ De hecho, la apropiación de temas y motivos en la creación pretendidamente propia, tan habitual en ese tiempo, no fue nunca negada por el propio Larra. Para este la originalidad radica, precisamente, en la mejora literaria del hipotexto y en su ajuste al ámbito concreto de recepción al que se orienta, como suele ser habitual en las adaptaciones del teatro francés en España desde los años veinte del XIX. ${ }^{8}$ Sintomática es, en este sentido, la defensa que Fígaro hace de su No más mostrador, relacionado por la crítica coetánea con Les adieux au comptoir, de Scribe:

[...] cayó en mis manos aquel vaudeville en un acto corto de Scribe. [...] apodereme de la idea y, haciéndola mía por derecho de conquista, escribí el No más mostrador en cinco actos largos; hice más: habiendo encontrado en Scribe dos o tres escenas que desconfié de escribir mejor, las aproveché $[\ldots],{ }^{9}$

aun cuando, a juicio de Correa Calderón, en esta adaptación «el robo va seguido de asesinato». ${ }^{10}$

Para Durnerin en la dramaturgia de Larra pueden distinguirse dos etapas: la primera comprendería hasta 1834, año en que se pone en escena Macías; la segunda, interrumpida por su muerte, se caracterizaría por el incremento de la actividad como traductor, en detrimento de la producción original. ${ }^{11}$ Es en este contexto en el que han de considerarse sus adaptaciones. Las más numerosas son las de Scribe: No más mostrador, 1831; Felipe (de Scribe, Mélesville y Bayard), 1832; El arte de conspirar, 1835;

6 Para esta dialéctica véase L. Behiels, «Larra, crítico de traducciones», Livius. Revista de Estudios de Traducción, 3 (1982), pp. 19-30 y M. P. Espín Templado, «Una falsa contradicción: Larra crítico de las traducciones teatrales y autor de las mismas», en J. Álvarez Barrientos, J. M. Ferri Coll y E. Rubio Cremades (eds.), Larra en el mundo. La misión de un escritor moderno, Alicante, Universidad de Alicante, 2012, pp. 237-254.

7 L. Romero Tobar, «Estudio preliminar», Textos teatrales inéditos, Madrid, CSIC, 1991, pp. 7-50, aquí p. 22.

8 L. Iglesias Feijoo, «Larra, dramaturgo y narrador», Larra. Fígaro de vuelta. 1809-2009, Madrid, Sociedad Estatal de Conmemoraciones Culturales, 2009, pp. 129-151, aquí p. 137.

9 M. J. de Larra, «Vindicación», La Revista Española, 23 mayo (1834).

10 E. Correa Calderón, «Larra y su sorprendente popularidad», Papeles de Son Armadans, XIX-LXXIV, nCCXXI-II (1974), pp. 155-165, aquí p. 161.

11 J. Durnerin, «Larra traducteur et adaptatuer du théâtre français», en F. Lafarga, C. Palacios y A. Saura (eds.), Neoclásicos y románticos ante la traducción, Murcia, Universidad de Murcia, 2002, pp. 285-296, aquí p. 290. 
Partir a tiempo, 1835; Tu amor o la muerte, 1836. De Ducange lleva a la escena española Roberto Dillon, o El católico de Irlanda, 1832; de Lockroy Un desafío o Dos horas de favor, 1834; de Delavigne Don Juan de Austria o La vocación, escrita durante la estancia de Larra en París, en 1835.

Para algunos críticos, la inclusión de esas piezas en sus Obras Completas, tanto en las decimonónicas editadas en Repullés (1837), Yenes (1843), Baudry (1848), Granier (1870) o Montaner y Simón (1886), como posteriormente, ${ }^{12}$ no está justificada. Correa Calderón opina que nada añaden a su gloria, que su maestría radica en el buen conocimiento del francés que revelan y que su fin no fue otro que el de ayudar económicamente al dramaturgo en tiempos difíciles. Económico es también el interés que, para Hespelt, guía la labor de Larra como traductor/adaptador de teatro foráneo. Pese a ello, «los resultados, como todo lo salido de su pluma, no nos deja indiferentes». ${ }^{13}$

Además de los títulos mencionados, desde la segunda mitad del siglo XIX se han ido dando a conocer otros, mayoritariamente inspirados en Scribe, que en su día permanecieron inéditos y en algunos casos tampoco se representaron. Así, Seco Serrano publica en el volumen IV de las Obras Completas del autor (1960) La madrina, estrenada en el coliseo de la Cruz en 1831, y Siempre. ${ }^{14}$ En 1978 Zviguilsky da noticia de Una imprudencia, de la que solo se conserva un acto. ${ }^{15}$ Ningún manuscrito se conoce de Despotismo, anarquía y libertad ni de Las desdichas de un amante dichoso, que sí se representaron. Romero Tobar edita en 1991 Julia, Los inseparables y El rapto. ${ }^{16}$

La traducción de Don Juan de Austria no fue la primera de Delavigne que vio la luz en español. Muy representada fue Las Vísperas Sicilianas (J. de la Pezuela, 1835); a ella le siguieron las adaptaciones de Marino Faliero (V. de la Vega, 1835), Los hijos de Eduardo (M. Bretón de los Herreros, 1835), Luis Onceno (P. de Gorostiza, 1836) y El Paria (J. García de Villalta, 1839). ${ }^{17}$

12 Para la descripción detallada del contenido de cada una de estas Obras Completas sigue siendo útil E. Cotarelo y Mori (1918), «Prólogo» a PostFígaro: artículos no coleccionados de Mariano José de Larra (Fígaro), Madrid, pp. V-LIV.

13 La afirmación es de L. Iglesias Feijoo, op. cit., p. 133. E. Correa Calderón, op. cit., p. 162. E. H. Hespelt, «The translated dramas of Mariano José de Larra and their French originals», Hispania, 15 (1932), pp. 177-134.

14 C. Seco Serrano (ed.), Biblioteca de autores españoles desde la formación del lenguaje hasta nuestros días. Obras de D. Mariano José de Larra (Fígaro), Madrid, Atlas, vol. IV, 1960, pp. 221-241 y pp. 243-267.

15 A. Zviguilsky (1978), «Une pièce inédite de Larra», Mélanges à la mémoire d’André Joucla-Ruau, Aix-enProvence, Université de Provence, vol. II, 1978, pp. 1237-1255.

16 Vid. L. Iglesias Feijoo, op. cit., pp. 129-151 y L. Romero Tobar, op. cit., pp. 7-48.

17 Recepción del teatro de Delavigne en Madrid en R. Dengler, «Casimir Delavigne (1793-1848), entre neoclásicos y románticos. Recepción de su obra teatral en Madrid de 1835 a 1845», en F. Lafarga, C. Palacios y A. Saura (eds.), Neoclásicos y románticos ante la traducción, Murcia, Universidad de Murcia, 2002, pp. $275-284$. 
En 1835, durante su viaje a Francia, Larra trata en París al entonces célebre dramaturgo y decide adaptar a la escena española su último drama, Don Juan d'Autriche, todavía inédito ${ }^{18}$ y que se estrena el 17 de octubre en el Théâtre Français. Antes, el 20 de agosto, en carta a Delgado, expresa su intención de escribir

[...] de Víctor Hugo, de Scribe y de Casimiro de la Vigne, tres cosas que están trabajando, y si son útiles, antes de que se impriman aquí, irán caminando en español para allá. (C. Seco Serrano, op. cit., p. 227).

Incluso prevé firmar alguna de ellas con seudónimo, como ya había hecho en ocasiones anteriores al ocultar su identidad tras la de Ramón Arriala:

Advierto a usted que en punto a traducciones tanto para el teatro como para la prensa me será preciso guardar el más severo secreto y anónimo en las que yo designe; si no no enviaré ninguna. En las que yo juzgue conveniente pondré mi nombre. Esta es toda mi riqueza y es preciso economizarla. (Idem). ${ }^{19}$

El 26 de noviembre explica a sus padres que ha debido retrasar su vuelta a España para recuperarse de la enfermedad que arrastra desde octubre y para traducir Don Juan de Austria:

No se ha publicado aún, aunque se ha representado; pero estando relacionado con el autor, he podido traducirla por el manuscrito y remitirla a la empresa de Madrid. (idem, p. 281).

El 5 de febrero de 1836, ya de vuelta y convertido en redactor de El Español, Larra publica una reseña al estreno de Teresa en la que declara la superioridad dramática de V. Hugo y A. Dumas, al tiempo que alude a Delavigne, alguna de cuyas composiciones juzga innovadora,

[...] y aun más su última producción, Don Juan de Austria, que debemos ver en breve en los teatros de Madrid. [...] no ha hecho sino una comedia heroica, en gran manera parecida a las de nuestro teatro antiguo, como El ricohombre y García del Castañar, mas sin haber podido igualarlas en mérito. Pero Casimiro Delavigne nunca podrá citarse como fundador. Molierista puro en La escuela de los viejos y en sus Cómicos, y volteriano en sus tragedias de Saria y Las vísperas sicilianas, es comedido en sus resortes dramáticos, parco y hasta parsimonioso; poco original, poco nuevo; templada su imaginación por la influencia de las reglas y su amor al orden, no es brillante ni arrebatado; en cambio es puro y correcto, moral como sus antecesores, y cuanto el teatro permite serlo. Es un río manso y sereno, puro y cristalino que, corriendo por un antiguo cauce beneficia el terreno que riega a fuerza de regarle. ${ }^{20}$

\footnotetext{
18 C. Delavigne, Don Juan d'Autriche, ou La vocation, par M. Casimir Delavigne, de l'Académie Française, Bruxelles, Hauman et Co., Librairies, 1836. En adelante cito por ella.

19 Hasta tal punto llega esta discreción que el propio Larra reseña dos dramas de Ramón Arriala: Tu amor o la muerte y Julia. A propósito de este segundo título opina, irónicamente, que «La traducción es de fórmula enteramente; medianita, como todas estas traducciones: se entiende y basta». («Teatros», Revista Española, 24 enero [1834]).

20 Fígaro, «Teatros. Príncipe. Teresa, drama en cinco actos, de Mr. Alexandre Dumas, y traducido por D. Ventura de la Vega», El Español, 123, 5 de febrero (1836), p. 4.
} 
Pero la representación que Larra anuncia no llega a producirse, acaso por desavenencias, desde tiempo atrás, con la empresa, a la que retira su propuesta dramática por no convenirle sus condiciones. ${ }^{21}$ Quizá ello explique que solo unos meses después, en mayo, Fígaro vuelva a mencionar Don Juan d'Autriche para subrayar, en este caso, la falta de rigor histórico de la obra, «la peor de todas evidentemente».22

Chaves y Nombela afirmaron en su día que Don Juan de Austria se había estrenado en el teatro del Príncipe el mismo año que Macías. C. de Burgos determinó que la obra no se lleva a escena hasta la primavera de 1836. Sin embargo, tal y como recuerda Romero Tobar, la Cartelera teatral madrileña revela que el drama no se representó en Madrid hasta los años cuarenta (13,16 y 18 de agosto, 1844; 4 de noviembre, 1844), aunque anteriormente había sido llevado a las tablas en Valencia, concretamente en 1837 ( 28 y 30 de noviembre; 2 y 24 de diciembre). ${ }^{23}$ Delgado edita por primera vez el texto también en 1837, meses después del fallecimiento de su autor. ${ }^{24}$

Las divergencias entre el original y la adaptación al español comienzan ya en el elenco, y no por los cambios operados en algunos nombres propios (Don Rodrigo Quesada por Don Quexada; don Pedro Gómez por don Ruy Gómes; Fray Lorenzo por Frère Pacome) o por la ausencia de otros en la adaptación («don Ferdinand de Valdés, archevêque de Séville, Inquisiteur Général»), sino por la mención explícita de Carlos $\mathrm{V}$ que, como tal, no figura en Delavigne, donde la presencia del emperador responde siempre a su identidad como monje en Yuste, esto es, Frère Arsène.

La intervención más generalizada que se efectúa sobre el hipotexto tiene que ver con la elisión de determinados motivos o situaciones. Sin embargo, en muchos casos estas reducciones no son sustanciales. Larra abrevia la enumeración de virtudes de Florinde que don Juan hace a Raphael o el ansia de riesgo y peligro de la que alardea el joven (I, 4); los gestos de coquetería de Florinde, que acaba de vestirse su traje de novia (II, 1); la exaltación de la generosidad de la muchacha que lleva a cabo su criada Dorothée (II, 3); las referencias de don Juan a personajes del Antiguo Testamento para

${ }^{21}$ L. Iglesias Feijoo (op. cit., p. 147) recuerda la información aportada en 1919 por Carmen de Burgos a propósito de la solicitud que Larra hace en abril de 1836 a la compañía de teatros, solicitando la retirada de su traducción.

22 Fígaro, «Teatros. Revista del mes de abril», El Español, 185, 3 de mayo (1836), p. 4.

${ }_{23}$ M. Chaves, Don Mariano José de Larra. Su tiempo, su vida, sus obras, Sevilla, Imprenta de La Andalucía, 1898; J. Nombela, Larra (Fígaro), Madrid, La Última Moda, 1906, p. 156; C. de Burgos, Fígaro. Revelaciones «Ella», descubierta. Epistolario inédito, Madrid, 1919, pp. 81-82; L. Romero Tobar, op. cit., p. 23. F. Herrero Salgado, Cartelera Teatral Madrileña II: años 1840-1849, Madrid, CSIC, 1963. Sobre las representaciones en Valencia, vid. L. Izquierdo, Cincuenta años de vida teatral en Valencia, Tesis Doctoral citada por L. Romero Tobar (idem).

24 Don Juan de Austria o La vocación, comedia en cinco actos y en prosa de Mr. Casimir Delavigne arreglada al castellano por don Mariano José de Larra, Madrid, Imprenta de d. José María Repullés, 1837. Cito por ella. 
ponderar su amor hacia la doncella cuyo origen judío acaba de descubrir (II, 6); la evocación de Carlos V que don Quexada hace tras su conversación con Philippe II (II, 10); el aderezo de Dorothée cuando sale de su casa hacia el tribunal inquisitorial («mantille»y «masque», IV, 2, p. 206; solo «manto» en la versión española, idem, p. 85).

La división de los actos en escenas es similar en ambos texto: en el acto II la escena diez del original se divide en dos en la versión española y produce, en adelante, una discordancia en el número de escenas (trece en Delavigne, catorce en Larra); en el acto III se suprime completamente la escena veintitrés francesa y en el IV la tres, de acuerdo en estos dos últimos casos con las «Variantes pour la représentation» que figuran como apéndice de la edición del drama tal y como se da a la imprenta.

En efecto, la edición de Don Juan d'Autriche ou La vocation que Louis Hauman publica en Bruselas en 1836 recoge (pp. 271-280) las diferencias textuales que se establecen entre el drama editado y el que se estrena en el Théâtre Français el 17 de octubre de 1835. Al contario de lo que ha señalado la crítica actual, la mayoría de las reducciones que el texto francés sufre en su traslación al español no son originales de Larra, sino que aparecen recogidas ya como variantes de la puesta en escena parisina de la pieza, ${ }^{25}$ a la que posiblemente Fígaro no asistió, pero cuyo texto manifiesta haber traducido durante el mes de noviembre posterior a la première. ${ }^{26}$

Este es el caso de la elisión, en el inicio de la obra, del post scriptum de la carta de Ignacio de Loyola a don Rodrigo, en el que el santo menciona, equívocamente, el placer infinito que le producen sus trabajos para llevar por el buen camino a las mujeres descarriadas de los Estados Romanos, suprimido en la representación parisina y en Larra:

[Don QueXadA:] Au fait, du côté maternelle il y a confusion, il y a foule; c'est ordinairement tout le contraire.

\{Post-scriptum: «Je vous disasis dans ma dernière lettre que je travallais d'un grand courage à la conversion de toutes les femmes égarées des États romains; vous apprendrez avec plaisir qu'elles me donnent infiniment de satisfaction». Homme charitable! J'en suis bien aise.\} (Remetant la lettre dans la portefeuille qu'il renferme). (I, 2, D. pp. 15-16; L. p. 5). ${ }^{27}$

\footnotetext{
${ }^{25}$ Las reducciones de Larra a las que voy a referirme lo son también, sin excepción, de la puesta en escena parisina, pero no todas las reducciones de esta pasan a la traducción. Quiere esto decir que sobre el texto de Delavigne la representación opera una serie de cambios (significativamente en el acto II) que no son tenidos en cuenta por Larra y que, por tanto, no resultan relevantes en la versión española.

26 En la carta a sus padres del 8 de noviembre afirma haber pasado veinte días muy enfermo en Iprés, «sin dejar la cama y sin poder escribir» (C. Seco Serrano, op. cit., p. 279). El 17 de noviembre les avisa de que su salida para España se ha retrasado por indicación de sus médicos (idem, p. 280). El 26 de noviembre les explica que, pese a estar casi recuperado se ha demorado unos días «para traducir aquí el Don Juan de Austria» (idem, p. 281).

27 En adelante coloco entre \{\} los fragmentos que las variantes para la representación suprimen en el
} 
Otro tanto sucede en la escena seis del primer acto. Felipe II aparece sobre las tablas -en el original y en la adaptación- como inclemente azote de herejes. Philippe II desea envejecer pronto y dejar de sentir pasión para poder concentrarse en los asuntos de Dios. El texto original subraya, con ironía, que su crueldad podría ser aún mayor de no ser víctima, él mismo, de una pasión amorosa no correspondida hacia una muchacha cuya identidad desconoce (y que resultará ser Florinda). La representación francesa y Larra, sin embargo, reducen buena parte del diálogo del rey con don Pedro (Gomès, en Delavigne) a la llegada de ambos a Toledo, eliminan los sueños de justicia divina que, en ese horizonte sin Florinda, alberga la mente del monarca, desvinculan su faceta pública de la privada y le dibujan como un tirano sin atenuantes en su conducta:

[Philippe II:] [...] Ah! Ce état ne peut durer; il est intolérable; il met en péril a vie dans ce monde et mon éternité dans l'autre. \{Oui, je vasi jusqu'à former des voeux contre moi-même...

GoMÈs: Vous, sire!

PHILIPPE II: Jusqu'à désirer qu'une vieillesse anticipée vienne tout à coup me glacer le coeur. Mes sens seraient éteints alors, et mes passions, seraient mortes. Je me plongerais dasn une idée unique, celle d'agrandir assez mes royaumes pour qu'il me devînt possible d'extiper de l'Europe jusqu'aux dernières racines du judaïsme et de l'hérésie. Alors, sourd à la voix des plaisirs et aux cris de la douleur, je n'entendrais que les ordres de l'Église. Je ferais passer par le fer et par les flammes tous ceux qui ne penseraient ni comme elle, ni comme moi, et me réjouissant dans mes oeuvres, j'aurais la conscience tranquile, l'Église me bénirait et je mourrais en chrétien.

GoMÈs: Plus tard, sire, dans biens des années, Dieu vous accorderaa cette grâce; mais aujourd'hui...\}

PhILIPPE II: C'est de toi que dépend mon répos et mon bonheur; fais que je la revoie [...] (I, 6, D. pp. 35-36; L. p. 14).

En el acto III la totalidad de las divergencias entre el texto de Delavigne y el de Larra proceden de las variantes para la representación a las que vengo refiriéndome: en las escenas dos y cinco diferentes fragmentos del diálogo entre Frère Arsène y Peblo, ${ }^{28}$

original de Delavigne y que tampoco pasan a la traducción de Larra, que en todos los casos se ajusta al texto resultante de dicha reducción. Anoto acto, escena y página del texto de Delavigne (D.) y la página de Larra (L.) en que puede leerse el resultado de esta elisión.

${ }^{28}$ A) Frère ARSĖNE: Ou qui connaissait le prix du temps; mais vous, quand vous ne le perdez pas, vous l'employez mal. / \{PeBLo, retournant vers le balcon d'unair mutin: J'aime mieux l'employer à dormir qu'à reveiller les autres. /Frère Arsène: Où allez vous...? Remuant sans cesse! /Peblo: Laissez-moi me recoucher, je ne remuerai plus. / Frère ARSĖNE: Eépondant toujours, même avant d'entendre. / Peblo, à part: Est-ce injuste? Quelquefois je ne réponds pas quand j'ai entendu. /Frère Arsène: Curieux à l'excès!\}/ Peblo: Comme s'il n'y avait que moi de curieux dans la maison. (III, 2, D. pp. 125-126; L. pp. 55).

B) Peblo: Vous avez tort, car le prieur s'est bien radouci depuis la mort du dernier abbé. \{J'entends les frères se conter entre eux que, malgré ses soixante-treize ans sonnés, il grille sous son air froid d'être nommé à la place vacante.\} Comme le chapitre se rassemble aujourd'hui pour l'élection, il ne dit plus mal de personne, afin de gagner des voix; [...]. (III, 2, D. p. 128; L. p. 56).

C) Peblo: Un prédicateur tout en Dieu,\{dont la figure ressemble à un sermon sur la charité, et dont les 
y entre Frère Arsène, Frère Timothée y Frère Pacome, ${ }^{29}$ sobre la pereza del joven y el ambicioso comportamiento de los monjes en Yuste, respectivamente; en la tres las reflexiones de Carlos V sobre el propio funeral que este ha organizado, haciendo correr la voz de su muerte, para romper la rutina de sus días en Yuste; ${ }^{30}$ en la diecinueve un breve fragmento del monólogo de Frère Arsène:

Je n'en puis pas dire autant de notre incorruptible procureur. \{Bon! Y a-t-il sous un capuchon une tête à l'épreuve d'un chapeaux? Mais\}... frère Pacôme, cet obstiné frère Pacôme cèdera-t-il? \{Eh! Oui; par peur, tout vieux marin qu'il est; le ridicule est l'épouvantail des gens du monde, et le scandale celui des hommes d'église\}. Je doute \{cependant\}; mon coeur bat, mon sang bouillonnne [...]. (III, 19, D. pp. 185; L. pp. 78).

La desaparición en Larra de parte de la escena veintidós y la totalidad de la veintitrés del texto original de Delavigne (acto III, pp. 192-196) es ya un hecho en el estreno de París. Con ello se suprime una circunstancia fundamental en el juego escénico del acto y determinante para la verosimilitud del conjunto: el afán de Frère Arsène por retener en su cuarto a los monjes el tiempo necesario para que don Juan pueda huir. Cuando este lo logra, anuncia su abdicación del cargo de prior para el que acaba de ser elegido y da por terminada la farsa gracias a la cual ha podido decretar en contra de las disposiciones de Felipe II- la salida del claustro de su hijo Juan. Tanto la representación francesa como la versión española aceleran la partida del joven, reducen la tensión dramática y aplazan la renuncia en el cargo del rey Carlos hasta más adelante.

El desenlace de este tercer acto, que se cierra contemplando el Emperador la huida de don Juan, al que afirma va a proteger siempre, es también una traducción del texto que sugieren las indicaciones para la representación, en este caso una adición a la versión primera de Delavigne:

FRÈrE ARSĖNE: J'En suis sorti à mon honneur! (III, 24, D. p. 196).

paroles sont plus douces que les bombons des soeurs de la Providence qui l'ont choisi pour directeur. / Frère Arsène, à part: Et avec raison.\} /Peblo: Eh bien! [...] (III, 2, D. pp. 129-130; L. p. 56).

29 A) FrÈre ArSÈnE: Bien volontiers, et le plus tôt possible. /FrÈre PACOME: \{Par Notre-Dame des Mariniers! Je m'y attendais. Vous aimez le changement, Frère Arsène; soit dit sans reproche./ FrÈrE ArsÈnE: Et vous vous plaisez à me le faire remarquer, frère Pacôme; soit dit sans aigreur.\} Peblo, je te dispense de l'office. Tu resteras ici pour recevoir le nouveau venu. (III, 5, D. pp. 137-138; L. p. 60).

B) FRÈre PACOME, avec dureté: Bon précepteur qu'il aura là. / \{FRÈrE ArsènE: Nous allons accomplir au chooeur une oeuvre importante, mes frères: celle d'implorer Dieu. [...] / PEBLo, à part: Ils sont rapatriés pour matines; notre saint patron y mettra du sien, si cela dure jusqu'à vêpres. / Frère ArsÈnE, à PACÔME: Ayez quelque pitié d'un malade, mon très cher gardien [...]. (III, 5, D. pp. 138-139; L. p. 60).

30 FRÈRE ARSÈnE: [...] C'est une idée que je veux exécuter en grand, avant que la nature la prenne avec moi tout-à-fait au sérieux\{: mes funerailles me feront passer une journée, une de ces journées dont les douze heures si vides, si longues, si lentes, ne commencent jamais assez tôt et finissent toujours trop tard. (Revenant sur le devant de la scène)\}. Enfin, la cloche sonne le premier office [...]. (III, 4, D. pp. 134135; L. p. 58). 
FRÈRE ARSÈnE, les yeux tournés vers la porte par laquelle DON JuAN vient de sortir: Va, bon et brave jeune home, de loin comme de près, je veillerai sur ta fortune (Descendant la scène). J'en suis sorti à mon honneur! (III, 24, «Variantes», p. 275).

Carlos V, vueltos los ojos hacia la puerta por donde acaba de salir don Juan. Pablo. CARLOS: Anda, mancebo generoso; así de lejos, como de cerca, siempre velaré sobre ti. (Viniendo hacia la orquesta) (III, 24, L. p. 82).

De las variantes proceden también las reducciones del acto IV a propósito del valor que Dorotea concede al dinero (Delavigne, IV, 1, pp. 199-200). La puesta en escena parisina y Larra prescinden tanto de la emotiva evocación del amor que Dorotea ha vivido con don Juan,

DONA FloRINDE: Le grand mérite! Je ne pense jamais qu'à lui. \{Nous nous sommes assis tant de fois parmi ces touffes de fleurs! Une pluie d'orage ne nous fesait pas peur alors; nous ne la sentions pas. Que de longues promenades, qui nous semblaient si courtes! Il n'y avait pour nous que belles nuits, que parfums, que bonheur! C'étaient de douces soirées qui ne reviendront plus.\} /DorothéE: Pourquoi? Ce seigneur en qui vous avez confiance ne vous a-t-il pas \{dit que le soupçon élévé contre vous [...]; enfin, n'a-t-il pas\} promis de vous ramener dans mes bras? / \{DONA FloRINDE: Et il tiendra sa parole [...], assurément l'inclination n'ysera pour rien.\} /DONA FloRINDE: Tais-toi, tais-toi;on vient; c'est celui que j'attends; j'aurai du courage. (IV, 1, D. pp. 202-204).

FloRINDA: ¡Gran esfuerzo, por cierto! Nunca pienso sino en él; mas ya jamás le veré./ Dorotea: ¿Por qué? ¿No prometió ese cortesano en quien fiais devolveros a mis brazos?/ Florinda: ¡Silencio! ¡Él es! ¡Valor, corazón! (IV, 1, L. p. 84),

como de la fría decisión de la muchacha a la hora de designarle como heredero de todos sus bienes en caso de morir a manos de la Inquisición (idem, D. pp. 203-204). Incluso la pequeña variación en el final de la escena dos procede de la representación en Francia:

DorothéE: Oh! Non: c'est un mot qu'il ne faut dire qu'à ceux qu'on ne doit pas revoir. (La reconduisant jusqu'à la porte et lui baisant les mains). Il vient malgré moi sur mes lèvres... Je ne le prononcerai pas; ma fille! Ma fille bien aimée...! (IV, 2, D. p. 206).

Dorothée, qui la reconduit en lui baisant les mains: Ma fille! Ma fille bien-aimée! (IV, 2, «Variantes», p. 276).

Dorotea (acompañándola, le besa las manos): ¡Hija mía!!! (IV, 2, L. p. 85).

Otro tanto ocurre con la reducción del monólogo de don Juan en la escena siete $^{31}$ los consejos de Gomès a doña Florinde en la nueve, ${ }^{32}$ la angustia de esta última

31 Don Juan, seul: [...] Réfléchissons, maintenant que je suis seul: à quoi me resoudre...? À l'attendre? [...] Mais je mourrais mille fois avant de m'en ouvrir l'entrée! \{N'est-ce pas le comble du malheur que de n'avoir pas même la ressource de faie une folie? [...] J'y succombe.] Ah! Florinde! Vous ai-je perdue pour toujours? (III, 7, D. 218; L. 89).

32 Dona FloRINDE: Hélas! Que peut-il attendre de la mienne? \{/Gomès: Je vous quitte, señora, et c'est encore pour m'occuper de vous; [...]Ayez donc autant de pitié pour vous que j'en ai moi-même.\} Don Philippe ne peut pas tarder: vous allez le revoirM vottre sort est dans vos mains. Restez, restez, señora. 
en la diez ${ }^{33}$ o los extremos pasionales de Felipe II hacia la muchacha: la escena quince del acto IV original se reduce en el texto español, de acuerdo con las indicaciones de las variantes, a unas simples líneas que preparan el desenlace. Se eliden, pues, los lamentos amorosos y atormentados del rey que desea a una judía, su humillación por la ofensa que don Juan le inflige al saberse preferido por la muchacha, la envidia de saber que Carlos I conoce a su bastardo y le distingue con la espada de Francisco I que a él mismo le ha negado insistentemente. Sirva como muestra de ello un breve ejemplo:

PHILIPPE II: Ma rage si long temps comprimée peut donc enfin se donner carrière...! [...] Il a levé sur moi cette épée... Que vois-je? Regarde, Gomès: je ne me trompe pas; mes ordres sont arrivés trop tard pour l'empêcher de parler à Charles-Quint [...]. (IV, 15, D. pp. 241-243).

PhILIPPE II, les yeux encore fixés sur l'arme qui est toombée des mains de DON JuAN: Il a levé sur moi cette épee...! Que vois-je? Regarde, Gomès: je ne me trompe pas; mes ordres sont arrivés trop tard pour l'empêcher de parler à Charles-Quint [...]. (IV, 15, «Variantes», p. 277).

FeLIPE II (los ojos clavados sobre el arma que dejó caer DON JuAN). Osó levantar contra mí esa espada...! Mas ¿qué veo? Reparad, don Pedro, no me engañan mis ojos;. Mis órdenes llegaron tarde para impedir que viese a Carlos V [...]. (IV, 15, L. pp. 100-101).

La escena uno del último acto larriano difiere notablemente del original en su versión primera, si bien se ajusta fielmente a las variantes que la edición de la pieza incorpora como apéndice. Así, desaparece el motivo de la carta que Felipe II redacta al inicio para Isabel de Valois, fingiendo amor y cortesía hacia la dama (D. p. 245; L. p. 102), y que al final de la misma encomienda a don Gomès. ${ }^{34}$ En la representación y en la adaptación española las primeras y las últimas palabras del monarca en la escena se refieren, por el contrario, a los condenados por la Inquisición, lo cual explica la preferencia de Larra por este planteamiento alternativo, acorde con la elisión general de lo francés que caracteriza a la traducción.

También aparece indicada como variante en el texto de Delavigne la supresión íntegra de la extensa escena tres del acto V (D. pp. 250-253), que detalla los extremos del auto de fe que se prepara y que Felipe II va a presidir, así como la modificación del parlamento inicial del rey en la escena siguiente, soluciones ambas adoptadas asimismo por Fígaro, cuya traducción se ciñe, en todos estos casos, a la versión que ofrecen las «Variantes pour la représentation» (pp. 271-280).

(IV, 9, D. pp. 222-223; L. p. 91).

33 Dona FLoRINDE, seule: \{Jen'ai plus qu'une espérance; mais queva-t-il m'ordonner? De renoncer à don Juan; ne sommes-nous pas séparés? De ne plus l'aimer; n'est-ce en mon pouvoir...?\} Oh! Que la terreur d d'empire sur nous! (IV, 10, D. pp. 223-224; L. p. 92).

34 Écrivez à la jeune reine en mon nom, ce qu'il vous plaira; je signerai sans lire (V, 1, D. pp. 248). 
Al margen de estas, en el texto español podemos rastrear un grupo de reducciones con respecto al original -menor en número, pero cualitativamente significativo-, que proceden, estas sí, de la voluntad de Larra. Tal es el caso de la caracterización del personaje principal, del que Fígaro suaviza sus manifestaciones antisemitas. Pretendidos juegos galantes como

Don JuAn: Si elle l' était [juive], je la ferais brûler vive.

DoROTHÉE, efrayée: Que dites-vous là?

Don Juan: Pour être un moment seul avec vous.

(II, 3, D. pp. 80-81),

desaparecen en la versión española, pero no la adscripción del protagonista a un círculo de amistades claramente xenófobas.

También elide Larra intervenciones que subrayan el carácter impulsivo del protagonista, como ocurre en el encuentro de don Juan con Frère Arsène. La euforia del muchacho que se ve protegido por quien es - sin que él lo sospeche aún- su padre, le hace expresar su deseo de llevar ante el anciano a su enamorada Dorotea:

DON JUAN: [...] Je reviendrai vous voir, je reviendrai avec elle...

FRÈrE ARSÈne, en souriant: Vous oubliez, don Juan, que les femmes ne pénètrent pas dans cette maison.

Don JuAn: Pardon! (Á part). Et une juive! J'avais là une belle idéee. (D. III, 9, pp. 156).

Se simplifica, asimismo, un breve diálogo entre Peblo/Pablo y don Juan. El muchacho muestra al protagonista una llave con la que huir. En el original francés la peripecia es más singular que en la versión de Larra:

Delavigne

Larra

Peblo: Avec cette clé...

Pablo: Con esta llave...

DON JuAn: Après?

PebLo: Par cette fenêtre...

Don Juan: On saute, et on est libre.

Peblo: Non; on tombe et on casse le cou; mais...

Don Juan: Achevez!

Don Juan: Acabad

Peblo: Silence! Voici frère Arsène.

PABLo: ¡Silencio! He aquí al padre

DON JUAN: Je ne saurai rien.

DON JUAN: Está visto: no lo sabré

Peblo, chantant.

PABlo (canta a media voz un villancico).

(III, 7, p. 144).

(III, 7, p. 62). 
El villancico francés que el muchacho canta, en fin, desaparece de la traducción, que posiblemente confiaría a los responsables de la puesta en escena la disposición musical de esta y las demás piezas que podrían haber acompañado al drama:

Comme un ange il était beau, no, no.

Comme un ange il était beau,

Noël nouveau! (III, 7, D. p. 144).

Explica Lorenzo-Rivero que Larra elimina las alusiones a la superioridad del rey francés para «convertir la comedia en un producto con fines españoles». ${ }^{35} \mathrm{En}$ efecto, la supresión de los diálogos relacionados con la exaltación de Francisco I es sistemática. El primero de ellos, en la escena catorce del tercer acto, reduce a unas líneas un parlamento extenso entre el Emperador y don Juan. Este alaba del francés su valor y caballerosidad, su autoridad como guerrero frente al superior talante político de Carlos V. Frère Arsène, complacido ante la arrogancia del muchacho, sentencia: «Je comprends qu'à vingt ans on péfère François I et qu'on aime mieux Charles-Quint à quarante» (III, 14, D. p. 166). Fray Arsenio, por el contrario, nada dice al respecto.

Del mismo modo, en la escena siguiente don Juan reclama la espada que cuelga en la pared del cuarto del monje. El texto francés señala que se trata del arma del rey, en su día prisionero de Carlos. La equiparación de la fiereza del muchacho y la del monarca galo (III, 15, D. p. 168) desaparece también de la traducción larriana, que aplaza hasta la escena veintiuna la entrega de la espada a don Juan, y no como representación del valor de Francisco I, sino del poder del Emperador: «Húbola por derecho de conquista [...] en una jornada bien gloriosa para las armas españolas» (III, 21, L. p. 80).

La adaptación del texto a la sensibilidad española de 1835, inmersa en convulsiones políticas y sociales muy graves, lleva a Larra a incluir en su adaptación críticas a determinadas realidades de su tiempo, que han sido analizadas por LorenzoRivero, como el papel censor que desempeña el director de Correos, la política cainita del carlismo, el fanatismo religioso y el materialismo eclesiástico. ${ }^{36}$

Los arreglos a que Fígaro somete un texto como Don Juan d'Autriche son, en definitiva, sintomáticos de sus ideas sobre lo que ha de ser una traducción bien hecha, pero menos originales, en su conjunto, de lo que hasta ahora ha subrayado la crítica. Con todo, la intensidad expresiva que Larra confiere a los personajes, la precisión

\footnotetext{
35 Lorenzo-Rivero, «La sátira de Larra en el Don Juan de Delavigne», Estudios Literarios sobre Mariano José de Larra, Madrid, José Porrúa Turanzas, 1986, pp. 89-101, aquí p. 93.

36 Idem, pp. 96-101.
} 
léxica de los diálogos y el agudo sentido crítico con que se trata el pretexto histórico que sirve de punto de partida hacen que la adaptación supere claramente al original. Como el mismo Fígaro afirma, basta tener un alma bien templada y gusto literario para comprender las bellezas de un drama histórico, «pero es preciso ser poeta para traducir bien a un poeta». ${ }^{37} \mathrm{Su}$ Don Juan de Austria parece darle da la razón.

\section{Bibliografía}

AYMES, J. R. «Las opiniones acerca de las traducciones en la prensa española de los años 1823-1844», Neoclásicos y románticos ante la traducción, en F. Lafarga, C. Palacios y A. Saura (eds.), Murcia, Universidad de Murcia, 2002, pp. 35-58.

«Mariano José de Larra et la traduction, ou comment accomoder la pratique à la théorie, et vice versa», Bulletin Hispanique, 104-2 (2002), pp. 829-849.

«Larra y el arte de traducir en materia de teatros», Boletín de la Biblioteca de Menéndez Pelayo, XXXV (2009), pp. 233-246.

BeHIELs. L., «Larra, crítico de traducciones», Livius. Revista de Estudios de Traducción, 3 (1983), pp. 19-30.

Burgos, C. de, Fígaro. Revelaciones «Ella», descubierta. Epistolario inédito, Madrid, 1919,

Chaves, M., Don Mariano José de Larra. Su tiempo, su vida, sus obras, Sevilla, Imprenta de La Andalucía, 1898.

Cobos CASTRO, E., «Teatro y traducción en el siglo XIX: el papel evaluador de la crítica teatral», Estudios de Investigación Franco-Española, 12 (1995), pp. 11-52.

Correa Calderón, E., «Larra y su sorprendente popularidad», Papeles de Son Armadans, XIX-LXXIV, nºCXXI-II (1974), pp. 155-165.

DENGLER, R., «Casimir Delavigne (1793-1848), entre neoclásicos y románticos. Recepción de su obra teatral en Madrid de 1835 a 1845», Neoclásicos y románticos ante la traducción, en F. Lafarga, C. Palacios y A. Saura (eds.), Murcia, Universidad de Murcia, 2002, pp. 275-284.

DurNERIN, J., «Larra traducteur et adaptatuer du théâtre français», Neoclásicos y románticos ante la traducción, F. Lafarga, C. Palacios y A. Saura, eds., Murcia, Universidad de Murcia, 2002, pp. 285-296.

Espín Templado, M. P., «Una falsa contradicción: Larra crítico de las traducciones teatrales y autor de las mismas», en J. Álvarez Barrientos, J. M. Ferri Coll y E. Rubio Cremades (eds.), Larra en el mundo. La misión de un escritor moderno, Alicante, Universidad de Alicante, 2012, pp. 237-254.

Herrero Salgado, F., Cartelera Teatral Madrileña II: años 1840-1849, Madrid, CSIC, 1963.

37 Fígaro, «De las traducciones», El Español, 132, 11 de marzo (1836), p. 3. 
De París al Madrid de la regencia: Don Juan de Austria o la adaptación larriana de Delavigne (1835-1837)

Hespelt, E. H., «The translated dramas of Mariano José de Larraand their French originals», Hispania, 15 (1932), pp. 177-134.

Iglesias Feijoo, L. «Larra, dramaturgo y narrador», Larra. Fígaro de vuelta. 1809-2009, Madrid, Sociedad Estatal de Conmemoraciones Culturales, 2009, pp. 129-151.

Lorenzo-Rivero, L., «La sátira de Larra en el Don Juan de Delavigne», Estudios Literarios sobre Mariano José de Larra, Madrid, José Porrúa Turanzas, 1986, pp. 89-101.

Nombela, J., Larra (Fígaro), Madrid, La Última Moda, 1906.

Romero Tobar, L., «Estudio preliminar», Textos teatrales inéditos, Madrid, CSIC, 1991, pp. 7-50.

Seco Serrano, C. (ed.), Biblioteca de autores españoles desde la formación del lenguaje hasta nuestros días. Obras de D. Mariano José de Larra (Fígaro), Madrid, Atlas, vol. IV, 1960. 